Portland State University

PDXScholar

\title{
Cost Effectiveness of Articulated Buses When Passenger Time is Treated as a Cost
}

Anthony M. Rufolo

Portland State University

Follow this and additional works at: https://pdxscholar.library.pdx.edu/cus_pubs

Part of the Transportation Commons, and the Urban Studies and Planning Commons Let us know how access to this document benefits you.

\section{Citation Details}

Rufolo, Anthony M., "Cost Effectiveness of Articulated Buses When Passenger Time is Treated as a Cost" (1984). Center for Urban Studies Publications and Reports. 66.

https://pdxscholar.library.pdx.edu/cus_pubs/66

This Report is brought to you for free and open access. It has been accepted for inclusion in Center for Urban Studies Publications and Reports by an authorized administrator of PDXScholar. Please contact us if we can make this document more accessible: pdxscholar@pdx.edu. 
COST EFEECTIVENESS OF ARTICULATED BUSES

WHEN PASSENGER TIME IS TREATED AS A COST

Anthony M. Rufolo*

* Thanks go to Ken Dueker for helpful comments on an earlier draft, and to Doug Wentworth both for comments and for providing data. This study was partially funded by the Department of Transportation, urban Mass Transportation Administration, Grant No. OR-11-øøø2.

August, 1984 


\title{
COST EFEECTIVENESS OF ARTICULATED BUSES \\ WHEN PASSENGER TIME IS TREATED AS A COST
}

\author{
Anthony M. Rufolo
}

\section{Introduction}

As the difference between fares and costs has increased over time, transit agencies have searched for ways to cut the cost of service. One method that is now being tried by some transit properties is the use of articulated buses. The larger size of these buses allows one driver to serve more passengers. Thus, there is a tradeoff between higher capital costs for the bus and lower labor costs per passenger mile in operation. Hence, the use of the articulated bus appears to be a move toward greater labor productivity by increasing the capital-intensiveness of transit.

The conclusion that articulated bus service is more capital-intensive may not be justified. The problem is that the analysis places no value on the time of the passenger. If the passenger's time is treated as an input into the transit process, then articulated buses may actually be more labor-intensive than standard buses.

This consideration of labor-intensiveness is important because the addition of the time supplied by passengers significantly raises the total cost of mass transit. Eurther, the shift from mass 
transit to private automobiles can be viewed as a shift to more capital-intensive production of transportation; and if the cost of capital continues to decline relative to labor cost, the more capital-intensive transportation mode will continue to draw additional passengers. Hence, if the articulated bus really is more labor-intensive than the standard bus the use of this more labor-intensive transit mode may further accelerate the shift to the automobile.

One recent study [Albright (1982)] concluded that articulated buses are cost-effective as substitutes for standard buses on a two-for-three basis but that this conclusion might change if service characteristics were considered. specifically, articulated buses would have longer headways and greater in-vehicle travel time. The present study uses information relating to Tri-Met buses in Portland, Oregon to evaluate the impact of articulated buses on passenger travel and waiting time. The value of this time is then used with information on capital and operating costs to determine the cost-effectiveness of these buses when passenger time is included as a cost. These time costs will vary relative to total cost depending on the length of the route, number of stops, and so on. The effect of certain characteristics are analyzed to help determine the conditions under which articulated buses will be more cost-effective than standard buses. 


\section{Background}

Tri-Met, the portland transit agency, recently introduced articulated buses on a number of routes. Their intent was to relieve overcrowding by replacing standard buses with the articulated buses running on the same schedule. The alternative would have been to purchase additional standard buses and hire additional drivers.

This choice does not simply reflect a tradeoff between the cost of the larger buses and the operating expenses associated with more of the standard buses. Because of their size, the articulated buses require more time for passengers to pay fares, are slower in acceleration, and there are fewer in operation. Each of these factors will increase headway and/or travel time. It was hoped that the first disadvantage would be eliminated when Tri-Met switched to a new self-service fare collection method, but the preliminary evidence does not support this and the other time disadvantages remain.

The specific framework for analysis is a model developed by Baumol (1967). The model compares production over time in capital-intensive (progressive) and labor-intensive (non-progressive) sectors. He argued that costs in the non-progressive sector were bound to rise relative to costs in the progressive sector. The essential part of the argument is that additional capital in the progressive sector would increase output per worker and, hence, wages. Consequently, wages would have to 
go up in the non-progressive sector as well if it were to retain employees. However, the non-progressive sector could not achieve the same output gain as the other sector due to its inherent reliance on labor. The cost per unit of output would continually rise relative to costs in the other sector. He predicted that this mechanism would cause increasing problems in the public sector because of relatively fixed labor usage with rising wage rates and little opportunity for productivity improvement. 1 .

The important issues for providers of public services are relatively easy to identify in this context. The first is the ability to increase labor productivity through capital investments. The second is the income elasticity of the demand for the output. This is a measure of how much more of the service people want as their income rises. The third is the availability of substitutes for the public service and the potential for increased productivity in producing the substitute.

1 Baumol's initial interpretation of his model was that the labor-intensive industries (including government) would be forced to contract operations and possibly cease production. Keren (1972) later showed that Baumol had misinterpreted his model, for if the cause of the wage increases is the increasing productivity of the capital-intensive sector, then there will be a relative abundance of the output of that sector; and--depending on preferences--people may be willing to shift resources to the labor-intensive sector. They might actually want to buy more output at the higher price because of their higher incomes. Essentially, the added productivity in one sector made people better off, and this "income effect" in favor of more output might offset the "substitution effect" toward less output in the more costly sector. Baumol (1972) agreed with this amendment to his analysis but pointed out that in either case there could be significant pressures on local governments to increase taxes. 
If productivity increases in the private sector but not in the public sector, then people will switch to the lower cost, private output.

This model appears to be directly relevant to the operating expenses of a transit system, since a large part of operating expenses are labor costs. In addition, the ability to substitute capital for labor seems fairly limited. Yet while this analysis does not necessarily imply problems for government in general, it implies problems for transit. There are not good private sector substitutes for most government output, and where there is a good substitute it is usually produced the same way as the public output. However, there is a good private sector substitute for mass transit and mass transit is much more labor intensive than is private transportation. In particular, the output of a transit system is not the movement of a bus or train from one point to another. Rather, it is one of the inputs in the movement of a variety of people from their origin to their destination. The "labor time" of the passenger also goes into producing this product. There is no way to move a person from one point to another without having that person provide some time as an input. When this labor time of the passenger is taken into account as one of the costs of providing transit, the labor costs increase dramatically.

The inclusion of the passenger's labor time when added to Baumol's model indicates very clearly why transit will have more 
significant problems than most other public outputs. All transit is inherently labor-intensive, but private transportation is relatively more capital-intensive than is public transportation; and this capital-intensive means of producing transportation allows the individual to reduce the usage of his own time in producing "completed trips". Thus, while usage of articulated buses appears to be a more capital-intensive form of transit, it may actually be more labor-intensive when passenger time is taken into account.

In a recent study, Walters (1982) considers optimal bus size when passenger waiting time is explicitly taken into account. He concludes that standard bus sizes are probably already too large for most applications. This result stems directly from the tradeoff between headway and passenger waiting time. For simplicity, he assumes a fixed number of passengers arriving randomly. The larger the bus, the larger the headway and, hence, the larger the cost in terms of passenger waiting time. He also concludes, surprisingly, that the greater the density on a route, the more desirable smaller buses become. This is because waiting time per passenger becomes more important when there are many passengers. Therefore, Walters' analysis seems to argue strongly against the use of articulated buses.

A number of factors may alter this conclusion in practice. The first is that passenger waiting time is not necessarily proportional to headway. The longer the headway, the more likely 
a person is to plan the trip to the bus stop. Hence, average waiting time with a one-hour headway is not likely to be half an hour. Nevertheless, longer headways do impose additional costs on passengers since they may not be able to travel at the desired time. The second is that distance between stops is also crucial in comparing buses of different sizes. Larger buses are more desirable when stops are widely spaced and there is little interim boarding and departing.

Walters presents only casual empirical evidence in support of his model, and the model contains a number of simplifications which may affect the final conclusions. The empirical work presented here allows for some testing of the sensitivity of walters' conclusions, and it begins to quantify the factors which have the most impact on the cost-effectiveness of articulated buses.

The labor time of the individual has been taken into account in studies of the demand for public versus private transportation; but in comparing articulated and standard buses, it appeared to be more feasible to treat the number of passengers as essentially fixed and then compare costs between the two systems. Thus, the passenger time-costs are estimated under various assumptions and these costs can then be related to previous studies of articulated versus standard buses. 
$\underline{\text { Research Design }}$

Articulated buses cost about $\$ 231, \emptyset \emptyset \emptyset$ compared to between $\$ 130, \emptyset \emptyset \emptyset$ and $\$ 14 \emptyset, \emptyset \emptyset \emptyset$ for standard buses. The buses get 3.6 and $4 . \emptyset$ miles per gallon respectively and drivers of the articulated buses get a fifty-cent per hour wage premium. Relative maintenance expenses have been estimated by Albright, et al., (1982). Since articulated buses replace standard ones on approximately a two for three basis, this ratio was used in all calculations in this study.

of course, expansion of service might not actually result in a three for two ratio of standard to articulated buses. A number of factors made the larger buses an attractive way to increase capacity on certain routes. An important attraction of the articulated buses was that schedules did not have to be changed. The articulated buses simply replaced standard buses on the same schedule. This also simplified matters where coordination of routes was important. offsetting this convenience is the fact that such usage does not necessarily imply that the buses are being used most efficiently. Recently, some schedule changes have been made to more effectively utilize the articulated buses. Given the difficulties inherent in rearranging schedules and determining optimal usage of equipment, it will simply be assumed that the three for two equivalence is appropriate.

other factors may conceptually have some impact but are likely to 
be unimportant in practice. In a larger bus there is no reason to expect more frequent breakdown than with a standard bus; and the larger number of people kept waiting when a bus breaks down should be exactly offset by fewer total breakdowns due to fewer buses. However, the longer headways associated with the use of larger buses implies that once a breakdown occurs, the time cost to passengers will be larger. Nevertheless, such issues are not addressed in this study.

The major part of the study was a simulation of the changes in passenger travel and waiting time when articulated buses substitute for standard buses on a hypothetical new timetable. All actual data are from before the articulated buses were placed in service, and the articulated bus results are determined by the simulation. The new timetable required that the last bus of the day leave at the same time as on the real schedule. The other buses were scheduled so as to maintain the approximate time pattern of the original schedule. For example, if there were an exact two-for-three replacement, the first new bus would be scheduled midway between the old first and second buses. The second bus would then be scheduled at the time of the old third bus, and so on. If the original schedule did not allow for an exact two-for-three replacement, the number of hypothetical articulated buses was rounded up. Passengers were allocated to buses on the basis of the relative times. For example, if a new bus ran between two old buses, it would be assigned all passengers from the first bus not previously assigned plus a percentage of 
the second bus' passengers, with the percentage determined by the relative time. It was assumed that the total number of passengers on each line was fixed, and did not decline due to the less frequent service.

Once the number of passengers was determined, the boarding and exiting pattern was used to determine changes in aggregate travel and waiting time. The pattern of boarding and exiting came from a Tri-Met origin-destination survey. This survey provided a sample of origin-destination pairs for each line based on four time periods. Preliminary analysis showed no differences in boarding and exiting patterns by time of day, so this data was aggregated into a single boarding and exiting profile for each line to improve its statistical reliability. Unfortunately, the data was not available on a bus stop basis; it was only available by census tract. Hence, the breakdown was not as fine as would be desirable. It was simply assumed that each bus stopped once in each zone and that all passengers from that zone either got on or off at that one stop. This creates a slight bias toward increases in travel time; but the bias only relates to people getting on and off in the same zone. It appears to be very slight given the actual pattern of boarding and exiting.

The final step in the simulation was to specify an average boarding and exiting time for passengers on standard and articulated buses and to specify the pattern of arrivals to wait for buses. The simulation was run under a variety of assumptions 
on four sample lines. The sample lines were chosen to represent both short-haul, high-density service and long-haul, low-density service.

$\underline{\text { Results }}$

Under standard fare collection procedures, articulated buses would be slowed by the collection of more fares per bus and the boarding and exiting of more passengers. However, proponents of the larger buses argue that this slowing is not inherent in the bus but is rather due to inefficient use of the doors. They argue that better fare collection methods would allow for greater use of the buses' additional doors and that this could affect the impact of carrying a larger number of passengers.

The empirical evidence does not support this contention. For example, Albright et al. (1982) found very slight reduction in dwell time per passenger with articulated buses. Their estimated coefficients aropped from . $\varnothing 38$ minutes per boarder for conventional buses to.$\varnothing 34$ for articulated buses; and they estimated each additional departing passenger increased a conventional bus' dwell time by .ø31 minutes as compared to .ø29 minutes for an articulated bus. Even the preliminary results from Tri-Met's self-service fare experiment do not indicate much improvement in boarding and exiting time.

The travel time simulation was run under two assumptions. The first assumption was that the results from the Albright et al. statistical studies were the appropriate measure of boarding and 
exiting times for the two types of buses. This gave the articulated buses a slight time advantage per person, but this would be offset by the greater number of people boarding and exiting. The second assumption was that the articulated buses could indeed board and exit passengers twice as fast as standard buses.

The results are presented in Table 1. Under the most reasonable assumptions, the average passenger spends just under half a minute more on his journey due to the larger number of people per bus. This result is reasonably consistent across lines, although the highest estimate is more than fifty-percent higher than the lowest estimate. Alternatively, if the articulated buses could achieve the hypothetical doubling of boarding and exiting speed their passengers would actually get to their destinations faster. In this case, there would be time savings that average about one-half minute per passenger.

The increase in wating time associated with longer headways was the basis for walters' (1982) argument for smaller, more frequent buses. However, Walters assumed that passengers arrive randomly. Many transit planners argue that the random arrival pattern is not appropriate for longer headways. It is argued that that random arrival is reasonable for headways up to about ten minutes; but that planning for the bus keeps the average wait down after that. Thus, they put a limit of five minutes on the average waiting time. Even if this is correct for the majority of passengers, it 
seems to be too strict to apply for all headways, it would imply that passengers face no additional inconvenience from longer gaps than ten minutes between buses. However, there is clearly some inconvenience due to not being able to travel at the most convenient time or to those making connections.

Because of the above considerations, there were three different assumptions used to simulate the impact of articulated buses on waiting time. The first assumption was that of random arrivals. This implies passenger waiting time of one-half headway. The second assumption was that arrivals were random for headways of less than ten minutes but that five minutes was the largest average wait. The last assumption was the same as the second except that ten-percent of the headway beyond ten minutes was added to passenger waiting time to account for the additional inconvenience.

The results are presented in Table 2. Under the random arrival assumption, the switch to articulated buses causes the average passenger's waiting time to increase by about three minutes. However, if the maximum average wait is five minutes, the switch to articulated buses only increases the wait by about one-half minute per passenger. Adding ten-percent of the headway beyond ten minutes yields an increase in the average wait of about one minute.

Increases of one minute in waiting time may not seem like much; 
but one minute per passenger when aggregated over many passengers can add up to a considerable amount of time. Table 3 shows the impact per bus run of the changes in travel and waiting times under the various assumptions. As yet there are no clear patterns between lines and the aggregated totals still may not seem large. In order to consider the impact in a cost-effectiveness framework, these numbers must be converted to annual figures. This next step will be open to criticism on a variety of grounds, but there were no clearly superior alternatives. Most buses are not assigned to a particular run either on an ongoing basis or even for a particular day. Thus, trying to trace the annual impact of a particular bus would be almost impossible. Instead, the following procedure was used.

Buses are normally assigned to trains. A train consists of a number of runs, after which the bus is again available. For each line, some trains run for the entire day. The number of trips per day for such buses was used to estimate the total impact of one bus. This was then converted to an annual basis by assuming the bus would run for two-hundred days per year. Both of these assumptions are open to some question. Buses assigned to a particular line typically were scheduled for at least twelve hours of service for that day, but it is not at all clear that the average bus is in service for twelve hours per day. Further, the two-hundred days of service is arbitrary.

Despite these caveats, the results presented in Table 4 are 
instructive. First, the pattern between lines finally becomes clear. Lines 14 (and 114 ) and 53 are relatively short-haul, high density routes while lines 36 and 57 cover longer routes. It is clear that both the travel and waiting time impacts are greater on the short-haul routes. This is primarily because a bus on a short-haul route would carry more individual passengers in a day and the waiting time and travel time impacts per passenger are not sensitive to the length of the trip. Hence, the articulated buses have the least negative impact in aggregate terms on the long-haul routes.

Albright et al. estimate that using articulated buses in all-day service on a two-for-three replacement ratio yields an annual cost saving of about $\$ 5, \varnothing \emptyset \emptyset$. Compare this to the passenger time costs. The most reasonable assumptions are probably the standard travel time and the ten-minute plus ten percent for waiting time. valuing passenger time at only one-dollar per hour turns these cost savings into losses for both of the short-haul lines and a value of $\$ 2$ would turn it into losses for the long-haul lines. In fact, most estimates of the value passengers place on their time would exceed the $\$ 2$ value (Cherlow, 1981). Even with the more favorable ten-minute maximum assumption, the articulated buses barely remain as cost savers on the long-haul routes at $\$ 2$ per hour. 
Conclusions

Clearly the results of this study depend on a number of assumptions. Nevertheless, the general implications are that articulated buses impose a fairly large time cost on passengers in high-density, short-haul uses. They are at less of a disadvantage on the long-haul routes, but even here their cost-effectiveness comes into question when the value of passenger time is taken into account. In any case, those transit properties with articulated buses should consider concentrating them on their long-haul lines. Finally, while there is the potential to eliminate the travel time disadvantage of the articulated bus, only the most optimistic assumptions have the improvement in travel time offsetting the increases in waiting time. 
TABLE 1

Estimated Additional Travel Time Per Passenger (Minutes) Substituting Articulated Buses with Standard Buses ( 2 for 3)

$\begin{array}{lcc}\text { Lines } & \begin{array}{r}\text { Est. Boarding, Exit Times } \\ \text { Estimate }\end{array} & \begin{array}{r}\text { Est. Boarding, Exit } 2^{\text {Times }} \\ \text { Faster Boarding }\end{array} \\ 14 \text { in } & .59 & -.48 \\ 14 \text { out } & .36 & -.30 \\ 114 \text { in } & .61 & -.50 \\ 114 \text { out } & .37 & -.30 \\ 36 \text { in } & .46 & -.45 \\ 36 \text { out } & .40 & -.38 \\ 53 \text { in } & .37 & -.37 \\ 53 \text { out } & .41 & -.36 \\ 57 \text { in } & .38 & -.75 \\ 57 \text { out } & .38 & -.75\end{array}$

1. These estimates are based on boarding and exiting times of . $\emptyset 38$ and. 031 for passengers on standard buses and .ø34 and $\emptyset .029$ for articulated buses.

2. These estimates are based on the assumption that each additional passenger boarding or exiting an articulated bus would cause only half the delay found on standard buses. 
TABLE 2

Estimated Additional waiting Time per passenger (Minutes) substituting Articulated Buses with Standard Buses ( 2 for 3)

\begin{tabular}{|c|c|c|c|}
\hline Lines & $1 / 2$ Headway 1 & $\begin{array}{l}1 \varnothing \text { Min } \\
\text { Maximum }^{2}\end{array}$ & $\begin{array}{c}10 \text { Min. } \\
\text { Maximum } \\
\text { Plus } 10 \% 3\end{array}$ \\
\hline 14 in & 2.96 & .37 & .63 \\
\hline 14 out & 2.93 & .38 & .64 \\
\hline 114 in & 2.83 & .44 & .74 \\
\hline 114 out & 3.16 & .34 & .68 \\
\hline 36 in & 3.79 & .74 & 1.35 \\
\hline 36 out & 4.35 & $.4 \varnothing$ & 1.19 \\
\hline 53 in & 2.37 & .90 & 1.19 \\
\hline 53 out & 2.47 & .86 & 1.18 \\
\hline 57 in & 2.53 & .61 & $1 . \varnothing \varnothing$ \\
\hline 57 out & 3.33 & .47 & $1 . \varnothing 4$ \\
\hline
\end{tabular}

1. Passenger wait time is estimated at $1 / 2$ headway.

2. Passenger wait time is assumed to be no more than an average of five minutes due to people planning their arrivals.

3. Passenger wait time is assumed to be one-half headway up to five minutes, and to ten percent of the headway beyond ten minutes is added to average wait time. 
TABLE 3

Estimated Additional Passenger Travel Time and Waiting Time Per Bus Run (Minutes)

Substituting Articulated Buses with Standard Buses ( 2 for 3)

Travel Times

Lines

14 in

14 out

114 in

114 out Estimated $^{l}$ Baster Boarding $^{l}$

29

$-23$

17

30

18

15

36 in

36 out

17

15

18

21

25
$-14$

$-24$

$-14$

$-15$

$-17$

$-15$

$-16$

$-42$

$-42$

\begin{tabular}{|c|c|c|}
\hline $\begin{array}{l}1 / 2 \\
\text { Headway } \\
\end{array}$ & $\begin{array}{l}10 \operatorname{Min}^{1} \\
\text { Maximum }\end{array}$ & $\begin{array}{l}10 \mathrm{Miq} \\
+10 \%\end{array}$ \\
\hline 145 & 18 & 31 \\
\hline 140 & 18 & 30 \\
\hline 137 & 21 & 36 \\
\hline 148 & 16 & 32 \\
\hline 127 & 25 & 45 \\
\hline 189 & 18 & 52 \\
\hline 96 & 36 & 48 \\
\hline 111 & 39 & 53 \\
\hline 142 & 34 & 56 \\
\hline 218 & 31 & 68 \\
\hline
\end{tabular}

1. See explanation in Tables 1 and 2 . 
TABLE 4

Estimated Additional Passenger Travel Time and waiting Time Per Bus Per Day (Hours)

Substituting Articulated Buses with Standard Buses ( 2 for 3)

\begin{tabular}{|c|c|c|c|c|c|}
\hline & Travel & Times & & g Times & \\
\hline Lines & standard & $\begin{array}{c}\text { Faster } \\
\text { Boarding }\end{array}$ & $\begin{array}{c}1 / 2 \\
\text { Headway }\end{array}$ & $\begin{array}{l}10 \operatorname{Min} \\
\text { Maximum }\end{array}$ & $\begin{array}{l}10 \text { Min } \\
+10 \%\end{array}$ \\
\hline $14+114$ & 10.97 & -8.75 & 66.50 & 8.52 & 15.05 \\
\hline 36 & 3.47 & -3.47 & 34.23 & 4.67 & 10.51 \\
\hline 53 & 11.55 & -10.85 & 72.45 & 26.25 & 35.35 \\
\hline 57 & 4.22 & $-7.7 \varnothing$ & 33.00 & 5.96 & 11.37 \\
\hline
\end{tabular}

Per Year (Hours) Assuming $20 \emptyset$ Days Per Year

$14+114$

2,194

$-1,750$

13,300

1,704

$3, \varnothing 1 \varnothing$

36

694

$-694$

6,846

934

2,102

53

2,310

$-2,17 \varnothing$

$14,49 \varnothing$

$5,25 \varnothing$

$7,07 \varnothing$

57

844

$-1,540$

6,600

1,192

2,274

1. See explanation in Tables 1 and 2 . 
REEERENCES

Albright, Richard, et al. (1982), "Articulated Bus Report",

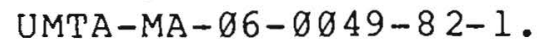

Baumol, William J. (1976), "Macroeconomics of Unbalanced Growth: The Anatomy of Urban Crisis", American Economic Review 57, pp. 415-426.

Baumol, William J. (1972), "Macroeconomics of Unbalanced Growth: Reply", American Economic Review 62, p. 150.

Cherlow, Joy R. (1981), "Measuring Values of Travel Time Savings", Journal of Consumer Research 7, pp. 36ø-371.

Cherwony, walter, et al. (1981), "Bus Route costing procedures: A Review", U.S. Department of Transportation, Urban Mass Transportation Administration, Report \# UMTA-IT-ø9-9ø14-81-1.

Keren, Michael (1972), "Macroeconomics of Unbalanced Growth: Comment", American Economic Review 62, p. 149.

Lee, Douglass B., Jr. (1974), "Costs of Urban and Suburban Passenger Transportation Modes", The Institute of Urban and Regional Research, University of Iowa, Working Paper \#14.

McEadden, Daniel (1974), "The Measurement of Urban Travel Demand", Journal of Public Economics 3, pp. 303-328.

MCGillivray, Robert G. (198ø), "Urban Bus Transit Costing", The Urban Institute, Working Paper 120ø-72-1.

Miller, Richard U., et al. (1978), "Labor Costs and collective Bargaining in Urban Mass Transit: problems of Definition, Measurement, and Resolution", in National Academy of Sciences, Transportation Research Board, Special Report 18l, Urban Transportation Economics (Washington, D.C.).

Pennsylvania House of Representatives (1980), "Report of the House Select Committee to Investigate SEPTA".

Selinger, Phil. "SSFC operating Impact Study: Phases I and II", Inter Office Memorandum, Tri-Met, September 23, 1982.

Walters, A.A. "Externalities in Urban Buses", Journal of Urban Economics, pp. $6 \not-72$. 